Featured Article

\title{
Managing apathy among people with dementia living in institutional settings: Staff's perceived gap between common and best practices
}

\author{
Feliciano Villar, PhD*, Karima Chacur, MSc, Montserrat Celdrán, PhD, Rodrigo Serrat, PhD \\ Departament of Cognition, Development and Educational Psychology, University of Barcelona, Barcelona, Spain
}

\section{A R T I C L E I N F O}

\section{Article history:}

Received 21 December 2020

Received in revised form 12 March 2021

Accepted 16 March 2021

Available online 3 April 2021

\section{Keywords:}

Apathy

Persons living with dementia

Long-term care

Staff reactions

\begin{abstract}
A B S T R A C T
The aim of this study is to explore how staff manage apathy involving a person living with dementia (PLWD). Forty-two staff members working in four Spanish long-term care facilities were interviewed; 21 were nursing assistants and 21 technical staff. They read a vignette about a PLWD presenting apathy. Participants were asked (1) how a situation like that is commonly managed, and (2) how it should be managed. Responses were content-analyzed. Most participants (88.1\%) mentioned having experienced a situation similar to the one described in the vignette. Behavior-focused strategies and person-centered strategies were the most frequently mentioned. As for best practices, person-centered strategies emerged as the preferred alternative, and technical staff mentioned them more frequently than assistant carers. Our findings stress the importance of organizational guidelines and staff development in the management of apathy in PLWD.
\end{abstract}

(C) 2021 The Authors. Published by Elsevier Inc. This is an open access article under the CC BY license

(http://creativecommons.org/licenses/by/4.0/)

\section{Introduction}

Among the behavioral and psychological symptoms of dementia, apathy is, without a doubt, one of the most frequent ${ }^{1}$, with a prevalence ranging from $24 \%$ to $90 \%$, depending on the level of severity of dementia (the more severe, the more frequent) and how apathy is conceived and measured. ${ }^{2}$ Despite its frequency and adverse effects on older adult's quality of life ${ }^{1}$, apathy is often ignored, or managed in very diverse ways. The present study is focused on how staff working in a Long-Term Care Facilities (L-TCF) manage apathy involving a person living with dementia (PLWD).

\section{Background}

Apathy and PLWD

Apathy in dementia is defined $\mathrm{as}^{4}$ 'an undesirable state of deficits in motivation, behavior, and emotional display, characterized by reduced-goal directed behaviors, cognitive activity, and emotions'. From a clinical point of view, apathy manifests as a lack of interest, initiative, and response to environmental stimuli, accompanied by social withdrawal and a flat emotional response.,

Apathy in dementia is associated with a variety of adverse effects ${ }^{1}$ : a reduction in the performance of activities of daily living, impoverished interpersonal relationships, deterioration of quality of

\footnotetext{
*Corresponding author.

E-mail address: fvillar@ub.edu (F. Villar).
}

life, and increased risk of mortality. ${ }^{7-9}$ It also predicts physical deconditioning ${ }^{10}$ and accelerated cognitive decline. ${ }^{11}$

Apathy also has a negative impact on caregivers, since people living with dementia (PLWD) showing apathy are less cooperative with care, difficult to engage with, and require more attention and monitoring. ${ }^{10}$ As a result, apathy in PLWD is particularly complex for caregivers to deal with, contributing to their care burden, burn-out, dissatisfaction with care, and depression. ${ }^{12-14}$ While studies of the severity, prevalence, and etiology of apathy in dementia are increasing, its management has received far less research attention. ${ }^{15,16}$ This paper aims to fill that gap, focusing on how staff in long-term care facilities manage PLWD showing apathy in their daily practice, and how they think that kind of behavior should be managed.

\section{Managing apathy in institutional settings}

Although apathy is one of the most common behavioral symptoms in dementia, it is often ignored by staff since, unlike other behavioral symptoms, such as aggressiveness and sexual disinhibition, apathy is less disturbing for caregivers and institutional functioning. ${ }^{17}$ In other cases, apathy is not correctly identified and some authors have identified a tendency to mistake PLWD with apathy for people with depression, ${ }^{18}$ which could imply that apathy is managed ineffectively or even not managed at all.

Despite this, there have been some studies evaluating interventions focused on apathy. Most of these interventions are focused on apathy as a behavioral symptom: they pose some kind of intervention (often included among the often described as 'non-pharmacological 
therapies, ${ }^{, 15}$ ) trying to directly stimulate PLWD showing apathy so that they can be 'reactivated'. However, such interventions are diverse in terms of the duration of the intervention, the target PLWD groups that they focus on, and the assessment methods they use. ${ }^{10}$ So, maybe not surprisingly, the results that are obtained are also diverse.

One of the most popular interventions used to counteract apathy and increase the level of participation of PLWD is music therapy. ${ }^{19,20}$ However, evidence about its efficiency is far from conclusive. While an early systematic review did not offer solid evidence of its utility in PLWD $^{21}$, more recent studies suggest that it does improve apathy and promote verbal and non-verbal communication ${ }^{22}$, particularly among PLWD in advanced stages of the disease. ${ }^{23}$ Similarly, art therapy has also been proposed to counteract apathy in PLWD ${ }^{24}$, although a recent review suggests that available evidence is still insufficient to confirm its efficacy. ${ }^{25}$ Pet therapy has also been used to improve apathy, and one study presented some promising results comparing apathy levels before and after an intervention using dogs. ${ }^{26}$ However, further research is needed to confirm the impact of this kind of intervention.

Cognitive and sensory stimulation have also been used to manage apathy. In the case of cognitive stimulation and training, although evidence is mixed ${ }^{27}$, some studies found that cognitive stimulation could diminish apathy in dementia ${ }^{28}$, particularly in the early stages of dementia. ${ }^{23}$ In contrast, in advanced stages of the disease, multisensorial stimulation such as the one provided through Snoezelen ${ }^{29,30}$ could be more efficient for managing apathy.

As well as specific interventions focused on apathy as a symptom and using organized, standardized and time-limited activities, apathy in institutional settings can be managed using a more personalized approach, based on two key aspects: firstly, taking into account the interests, preferences and competencies of PLWD ${ }^{31,32}$, and secondly, considering the role of the social context, as apathy is likely to be, at least partially, the result of the social and relational opportunities provided by the institution. ${ }^{33}$ Approaching apathy in this more holistic and tailored way is in tune with person-centered models of care, which emphasize the importance of knowledge of biographical preferences entrenched in an individual's life story, and respecting an individual's autonomy and decision-making capacity ${ }^{34}$, and highlights that psychosocial needs, patterns of relationship and environmental context have a decisive impact on the behavior of PLWD. ${ }^{35}$

Strategies in line with person-centered care models include engaging with PLWD showing apathy in everyday conversations ${ }^{36}$ or reminiscences ${ }^{37}$, which not only improves apathy but also diminishes stress and feelings of burden among staff members. ${ }^{38}$ One common challenge encountered when attempting to engage in this everyday interaction is the difficulty that PLWD may have in expressing their wishes. As a consequence, staff members should find alternative ways to explore their preferences and promote their participation in everyday tasks accordingly. Paying attention to non-verbal cues, such as gestures, smiles and other kinds of facial expressions is the usual advice. $^{33}$ Having determined which memories, activities, ways of social interaction, or aspects of the social context are particularly stimulating and attractive for each PLWD, using those elements in staff members' interactions with them seems to improve motivation and emotional well-being. ${ }^{39}$

\section{The role of staff in managing apathy in PLWD}

The role of staff and how they interact with PLWD in everyday life is key to managing apathy successfully, especially since in many cases PLWD in long-term care institutions end up depending on the structure and initiative provided by others to maintain their activity and interaction.

However, few studies have focused on how staff actually manage apathy in their daily practice, and which strategies, if any, they apply to resolve the situation. Such knowledge is key to detecting any kind of mismanagement, as well as providing clues to improve staff practices and thus avoid the negative consequences that apathy might have for PLWD. In this respect, it would be useful to differentiate between common practice (how staff generally manage cases of PLWD showing apathy, i.e. what they actually do) and best practice (how members of staff think apathy in PLWD should be ideally managed). As reported in other areas of intervention with PLWD involving communication ${ }^{40}$ or sexual behaviors ${ }^{41}$, if differences between common and best practices are great, the gap would indicate that there are barriers preventing staff from dealing with apathy in the way they should.

Regarding the management of apathy, one factor that could make a difference is the presence (or absence) of adequately trained staff. However, in the case of apathy, specific training is rarely offered, at least in comparison to other more perturbing or disruptive behaviors, such as aggressiveness or agitation. ${ }^{42}$ In this respect, the role that different professionals play within the long-term care institution is likely to have an impact on their approach and management of apathy in PLWD. Specifically, it could be useful to differentiate between technical staff and care assistants.

Technical staff members need to have completed university studies (in health-oriented disciplines such as Medicine, Nursing or Physiotherapy, or in more social-oriented ones, such as Psychology or Social Work) and they are responsible for supervising and deciding upon guidelines for dealing with challenging situations. They usually decide what constitutes a problem and what does not, and how certain situations need to be managed. However, the staff who encounter and have to cope with the situation are the care assistants, who provide support for PLWD in activities of daily living (e.g., eating, mobilizing or toileting) and have to deal with the difficult situation of PLWD who show apathy. Care assistants are generally less well trained (in Spain, for example, they have not completed university studies), less well paid, more vulnerable to stressful situations, and more affected by turnover and staffing shortages than technical staff. ${ }^{43}$ If apathy leads to an increase in the care burden, it will primarily have an effect on care assistants, rather than on technical staff.

As a consequence, the position of the staff within the organization involves a set of experiences, knowledge and responsibilities that are likely to fundamentally change the approach to and management of behavioral symptoms such as apathy. In fact, such differences among staff have been shown to be key in the handling of other challenging situations involving PLWD living in long-term care institutions, such as inappropriate sexual behaviors. ${ }^{44}$ However, as far as we know, to date no study has included this variable when considering the management of apathy in PLWD.

\section{Objectives}

This study had three objectives. Firstly, to explore how staff in an L-TCF manage apathy involving a PLWD. Secondly, to compare staff's views regarding how apathy is generally managed (common practice) and how they think it should be managed (best practice). Finally, to determine differences according to work position, by comparing technical staff and care assistants, both in common and best practices regarding apathy management.

\section{Material and methods}

\section{Design}

This is a Cross-sectional qualitative study, using the vignette technique and open-ended questions to gather data which were subsequently transcribed and content-analyzed. 
Sample

Participants in the study had to meet two inclusion criteria (1) having worked for at least one year in a L-TCF, and for at least six months at the current L-TCF, and (2) holding a position that involved direct care-based contact with residents, i.e., excluding maintenance, kitchen or cleaning workers. Forty-five staff members were approached by researchers. Forty-four gave their consent to participate and one declined. However, information provided by two participants (one man and one woman) were used for training purposes only (see below), and so the data analyzed in this study comprised the responses given by 42 participants.

The age of those 42 participants ranged from 22 to 62 years old $(\mathrm{M}=40.7, \mathrm{SD}=11.8)$ and they reported working in L-TCFs for between one and 30 years $(\mathrm{M}=8.47, \mathrm{SD}=7.9)$. Four Spanish L-TCFs that provide long-term care services to residents with or without a diagnosis of dementia participated in this study. Approximately the same proportion of care assistants and technical staff (including nurses, physiotherapists, psychologists and occupational therapists) were interviewed in each L-TCF. The sample consisted of 21 nursing assistants and 21 technical staff, and included 32 women and 10 men, a ratio that reflects the feminization of caregiving roles in L-TCFs in Spain. Table 1 shows a comparison among the four institutions participating in the study.

\section{Procedure}

L-TCFs were contacted and the study's objectives and procedure for data collection were explained to the management team of each L-TCF. Once their written authorization had been obtained, each institution provided a list of the staff workers who met the inclusion criteria. Participants were randomly selected from the list, in order to obtain the highest degree of diversity, making sure that the same proportion of care assistants and technical staff was selected for each institution. Although they were not explicitly informed, managers of each L-TCF knew which members of the staff finally participated in the study.

At the beginning of the interview participants were informed of the study objectives and were asked to sign a written informed consent form. The interviews were conducted individually in a single session for participant, and using a private office provided by each LTCF. The interviews were conducted by a research assistant, a female holding MSc in Gerontology and with wide experience in qualitative research involving older adults. She had a part-time job at the university at the time of the study and did not have a prior relationship with interviewees. She provided her name and professional's background to each person interviewed.

Before conducted the interviews analyzed in the study, the interviewer followed a specific training. She interviewed two staff workers who met the inclusion criteria, as part of her training activities. These results were discussed with the research team with the purpose of obtaining rich and reliable data. These initial interviews were not part of the final sample and were not analyzed as part of the study.

Once all interviews were conducted and results were obtained, we sent a brief report describing the major findings to managers of

Table 1

Description of participating institutions

\begin{tabular}{lllll}
\hline & L-TCF 1 & L-TCF 2 & L-TCF 3 & L-TCF 4 \\
\hline Number of interviewed technical staff & 5 & 6 & 5 & 5 \\
Number of interviewed care assistants & 6 & 4 & 5 & 6 \\
Size (number of beds) & 68 & 99 & 113 & 91 \\
Ownership & Public & Private & Non-profit & Non-profit \\
\hline
\end{tabular}

each participating institution and the members of staff interviewed, and prompted them to give feedback. Apart from their gratitude and expression of commitment to improve their care practices, we did not receive any significant feedback regarding the issues discussed in this paper. This project received approval from the Bioethics Committee of the [blinded for review].

\section{Measures}

Data were obtained by means of a semi-structured interview, constructed by the authors of this study. The interview addressed various aspects about the care practices for PLWD living in an L-TCF, and included some introductory questions about skills that were lost and remained in dementia. Then, all participants were presented with two vignettes related to complex situations that staff may be faced with in the process of caring for a PLWD. All interviews were done by an assistant researcher paid by the research project, and their duration depended on the participant, ranging between 30 and 50 minutes long. The interview guide is included in Appendix A.

According to the study objectives, only responses to the vignette about a PLWD presenting apathy were analyzed here. Participants were asked about the following vignette: "A person with dementia living in this L-TCF spends all day sitting, without talking to anyone, and refuses to participate in any activity proposed by the staff".

Participants were asked (1) Have you experienced an event like this in your time in this nursing home?; (2) If so, what do the workmates in their L-TCF commonly do in this situation?; and (3) What should be done in such a situation?

Answers were audiotaped and transcribed verbatim. To maintain the confidentiality of the data, a three-part code was used for each participant: the first letter corresponded to the participant's work position ( $C$ was used for care assistant and $T$ for technical staff), the second indicated the participant's gender ( $M$ for man and $\mathrm{W}$ for woman), and finally, the number indicated the age of the participant.

\section{Data analysis}

The answers were transcribed and content-analyzed. This type of analysis is useful to identify common themes in the responses, and to quantify the frequencies of these themes. ${ }^{45}$ This type of analysis is particularly suitable for exploratory studies, where the main objective is to explain people's experiences, generating concepts, instead of testing theoretical frameworks.

The content analysis included three phases. First, two researchers independently read the transcribed answers to become familiar with them. They tried to identify ideas (or units of meaning) in the answers. Each response could include one or more than one idea. Second, each researcher independently compressed the ideas into categories based on the similarity or reiteration among threads of meaning or the presence of similar keywords or expressions. Interpretative notes were made in the process, which finished when data saturation was reached, and no new meanings arose from the data.

Based on this task, two draft category systems with a hierarchical structure were generated: existing general categories and more specific categories within each of them, covering more nuanced meanings. The researchers compared a draft category system and discussed the differences until they reached a consensus. All ideas were coded using this category system.

Third, the category system and a randomly selected subsample were coded by third independent researcher who had not participated in the construction of the categories. He had to replicate the coding and compare it to the original. Differences were discussed and some categories were adjusted if necessary, in order to reach a consensus on how to properly code all the ideas. The frequencies of at 
least the first- and second-order categories were obtained, for common and ideal practices, and for both staff positions.

Two out of the three researchers involved in conducting the content analysis held PhD in Psychology, and the third one held MSc in Gerontology. All of them had broad previous experience in content analysis.

\section{Results}

Most participants (88.1\%) mentioned having experienced a situation similar to the one described in the vignette, and this percentage was similar among technical staff (85.7\%) and assistant carers (90.5\%).

Five main categories of responses (see Table 2) emerged from the content analyses, corresponding to five different reactions to or ways of managing apathy in PLWD living in a long-term care institution: (1) Behavior-focused Intervention (which included the second-order categories "promote participation" and "try specific activities"); (2) Person-centered Intervention (including the second-order categories "emphasis on the relationship" and "emphasis on needs and lifestory); (3) No Intervention; (4) Sharing the Situation with Someone (which included the second-order categories "inform or seek support from workmates" and "sharing with the family"; (5) Staff Diversity; and (6) Don't know/gave no answer.

\section{Behavior-focused Intervention}

Behavior-focused strategies included references to generic solutions addressed to counteract the specific situation presented as a problem (that is, apathy). This strategy was mentioned as a common practice by $47.6 \%$ of participants. Behavior-focused strategies also include secondary, more nuanced strategies. The promotion of participation, and providing specific kinds of activities to PLWD were mentioned (see Table 2 for specific examples).

\section{Person-centered Intervention}

Person-centered strategies referred to strategies or solutions that sought to determine and take into account how the PLWD may experience the situation (according to their needs, aims, life story, or other personal characteristics) in order to create a bond and/or find a tailored solution to apathy. This strategy was mentioned as a common practice by $45.2 \%$ of participants. Person-centered strategies also include secondary, more nuanced strategies: participants mentioned reinforcing the relationship with PLWD and taking into account their needs and life story (see Table 2 for specific examples).

\section{No Intervention}

No Intervention grouped answers that mentioned "doing nothing" as the response to PLWD presenting apathy. This strategy was mentioned as a common practice by $14.3 \%$ of respondents (see Table 2 for specific examples).

\section{Sharing the Situation with Someone}

Sharing the Situation with Someone included responses mentioning that the common (or best) practice for resolving situations of apathy was to consult other people who are better prepared or more informed, and who are able to take charge of the situation and provide a solution. These 'other people' might be workmates (members of the technical staff) or family relatives. Sharing the Situation with Someone was reported as the most common practice by $11.9 \%$ of participants (see Table 2 for specific examples).

\section{Staff Diversity}

Staff Diversity included answers stating that the response to PLWD presenting apathy depended on the person who had to deal with it, without going into more detail. This strategy was mentioned as a common practice in $4.7 \%$ of the responses.

\section{Don't know/gave no answer}

This category grouped responses in which the participants did not know what to say or did not mention any strategies or practices for addressing situations of apathy. Nineteen per cent of common practice responses were classified under this heading.

Table 2

Strategies applied for managing apathy shown by a PLWD.

\begin{tabular}{|c|c|c|}
\hline First-order category & Second-order category & Examples \\
\hline $\begin{array}{l}\text { (1) Behavior-focused } \\
\text { intervention }\end{array}$ & $\begin{array}{l}\text { Promote participation } \\
\text { Try specific activities }\end{array}$ & $\begin{array}{l}\text { "Insist" (AG-H-35), "Include them in activities, even though they only listen" (T-M-37), "Try to } \\
\text { motivate them" (T-M-29). } \\
\text { "Try knitting, drawing or other activities" (AG-M-57), "Stimulate them with some manual activity } \\
\text { or program" (AG-H-54), “Doing sensory stimulation" (AG-M-53). }\end{array}$ \\
\hline $\begin{array}{l}\text { (2) Person-centered } \\
\text { intervention }\end{array}$ & $\begin{array}{l}\text { Emphasis on the relationship } \\
\text { Emphasis on needs and life story }\end{array}$ & $\begin{array}{l}\text { "Talk with the person and provide company" (T-H-26), "Bond with them" (T-M-49). } \\
\text { "Find out the reasons and meaning of that behavior" (T-M-49), "Ask him about his motivations and } \\
\text { needs" (T-M-24),"Take into account his personality before joining the nursing home, and what he } \\
\text { has experienced in his life" (T-M-35) }\end{array}$ \\
\hline (3) No intervention & & $\begin{array}{l}\text { "I would say that the tendency is to let them be isolated" (T-M-29), "We leave them in the televi- } \\
\text { sion room for hours" (AG-M-40), "If the attitude persists, I suppose that. . you finally give up on } \\
\text { them" (T-M-48). }\end{array}$ \\
\hline $\begin{array}{l}\text { (4) Sharing the situation } \\
\text { with someone }\end{array}$ & $\begin{array}{l}\text { Inform or seek support from workmates } \\
\text { Sharing with the family }\end{array}$ & $\begin{array}{l}\text { "Inform the nursing team" (AG-H-47), "Tell the psychologist, he must know what to do" (AG-H-54). } \\
\text { "Talk with the family" (T-M-25), "Find relatives and ask them what they would do" (T-M-31). }\end{array}$ \\
\hline (5) Staff diversity & & $\begin{array}{l}\text { "Difficult to say. Some professionals worry a lot and try to do something (...) others simply don't } \\
\text { care" (T-M-31). }\end{array}$ \\
\hline $\begin{array}{l}\text { (6) Don't know/ } \\
\text { Gave no answer }\end{array}$ & & “I wouldn't know what to response. I simply don't know” (AG-M-31) \\
\hline
\end{tabular}


Table 3

Frequencies (percentages in brackets) of common and best practices according to work position.

\begin{tabular}{|c|c|c|}
\hline Categories & $\begin{array}{l}\text { Technical staff } \\
(\mathrm{n}=21)\end{array}$ & $\begin{array}{l}\text { Assistant carers } \\
(\mathrm{n}=21)\end{array}$ \\
\hline \multicolumn{3}{|c|}{ (1) Behavior-focused intervention } \\
\hline Common practice & $8(38.1)$ & $12(57.1)$ \\
\hline Best practice & $14(66.7)$ & $9(42.9)$ \\
\hline \multicolumn{3}{|c|}{ (2) Person-centered intervention } \\
\hline Common practice & $9(42.9)$ & $10(52.4)$ \\
\hline Best practice & $20(95.2)$ & $10(52.4)$ \\
\hline \multicolumn{3}{|l|}{ (3) No intervention } \\
\hline Common practice & $7(23.8)$ & $1(4.8)$ \\
\hline Best practice & $0(0)$ & $0(0)$ \\
\hline \multicolumn{3}{|c|}{ (4) Share the situation with someone } \\
\hline Common practice & $1(4.8)$ & $4(19.0)$ \\
\hline Best practice & $3(14.3)$ & $2(9.5)$ \\
\hline \multicolumn{3}{|l|}{ (5) Staff diversity } \\
\hline Common practice & $1(4.8)$ & $1(4.8)$ \\
\hline Best practice & 0 & 0 \\
\hline \multicolumn{3}{|c|}{ (6) Don't know/gave no answer } \\
\hline Common practice & $4(19.0)$ & $4(19.0)$ \\
\hline Best practice & $1(4.8)$ & $5(23.8)$ \\
\hline
\end{tabular}

Note: The sum of frequencies is greater than the number of participants because some participants' answers mentioned more than one strategy, each one coded into different categories.

\section{Comparison between technical and assistant care staff}

Responses given by the technical and assistant caring staff are shown in Table 3. When comparing frequencies, the greatest differences, in the case of common practice, appeared in three categories: technical staff (far more so than assistant carers) said that not intervening was a common practice, while the opposite happened in the case of behavior-focused strategies, which were mentioned more by assistant carers than by technical staff. Assistant carers also mentioned sharing the situation with a relative or workmate more often than technical staff.

\section{Comparison between common and best practices}

When asking about best practices, person-centered strategies emerged as the preferred alternative that should be used to manage apathy in PLWD (see Fig. 1), although behavior-focused strategies were also mentioned slightly more often as best practice in comparison to the mentions received in relation to common practice. No intervention or staff diversity were not mentioned as best practice.

As for the comparison between technical staff and assistant carers in terms of best practices (see Table 3), differences appeared in behavioral-focused strategies, which were mentioned more by technical staff, and particularly in person-centered care strategies, which were mentioned twice as often by technical staff than assistant carers. Assistant carers, in contrast, did not mention any best practice far more frequently than technical staff.

\section{Discussion}

This study was aimed at identifying how staff in long-term care institutions for older people manage apathy involving a PLWD, taking into account differences between common and best practices, and comparing views of technical staff and assistant carers.

Regarding the strategies mentioned by participants, almost all of them, regardless of their work position, had experienced a situation involving apathy in PLWD. This result confirms that apathy is one of the most frequent behavioral and psychological symptoms of dementia in persons living in long-term care institutions ${ }^{46,47}$ and suggests the relevance of paying attention towards how such situations are being managed. In this regard, the results highlight at least four important issues.

Firstly, the results show that participants mentioned more than a single strategy for managing apathy in PLWD, either for common or best practices. This diversity may indicate the lack of consolidated

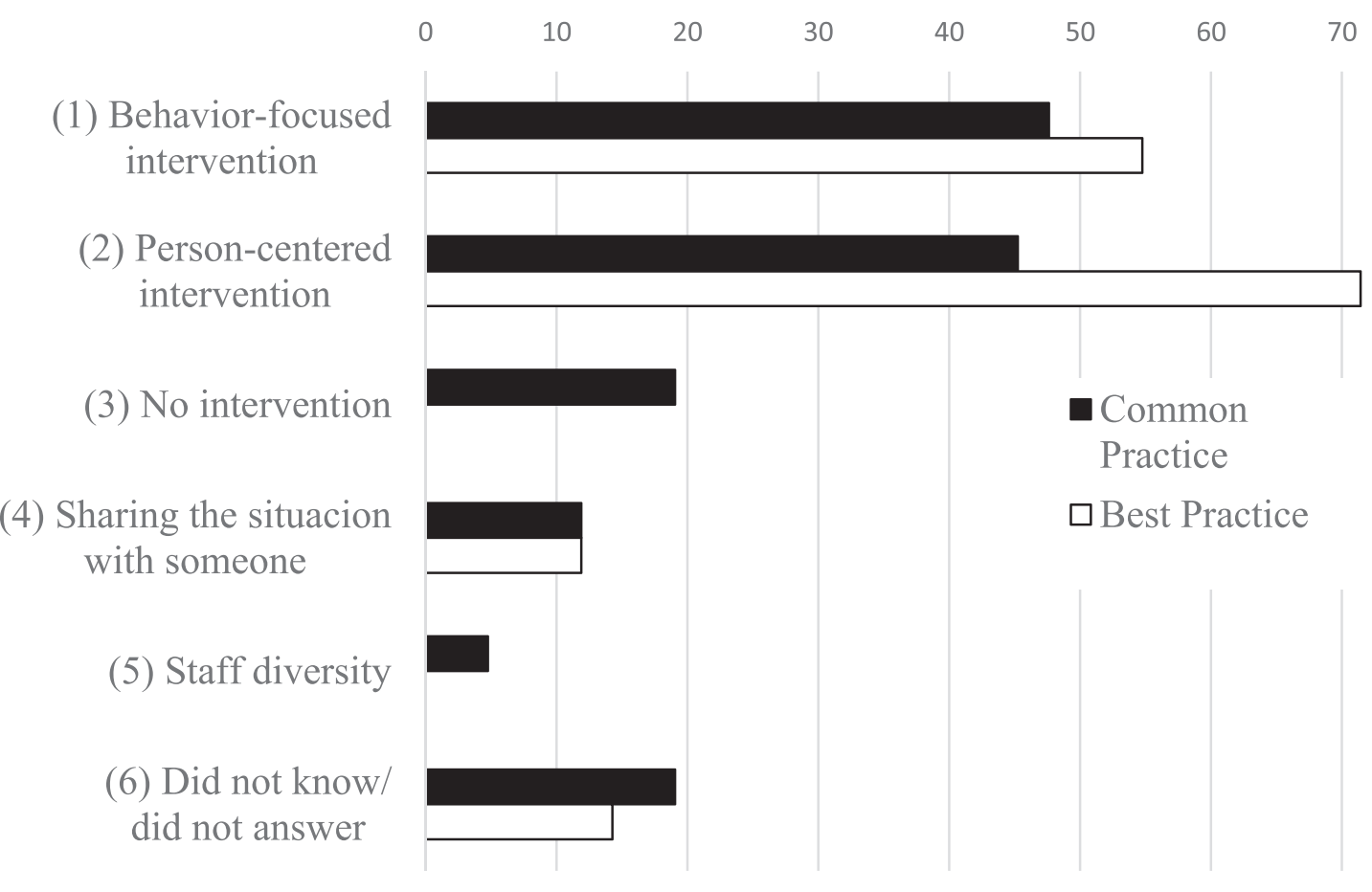

Fig. 1. Frequency (in percentage) of strategies to manage apathy in PLWD, chosen as common and best practices. 
policies or accepted guidelines among professionals, who seem to act according to personal criteria. That is, the response that a PLWD receives when showing apathy will depend greatly on the specific professional, either technical staff or assistant carer, who is in charge of their care and takes decisions on what to do. However, this diversity may also reflect the complexity of apathy, a state that may be precipitated by different factors in different individuals ${ }^{14}$ and may lead respondents to mention practices that may work only in certain situations and in certain people. As will be discussed below, our results do not suggest that a tailored intervention, chosen after taking into account the specific circumstances of the PLWD, is the dominant common practice.

Secondly, in the case of common practice, more than half of the participants said that apathy is managed using behavior-focused strategies. That is, when caring for a PLWD showing a lack of activity and motivation, the preferred strategy is maybe the most direct and simple: providing any kind of activity to stimulate them. Regardless of the effectiveness of behavior-focused strategies may have in some cases (the factor that probably explains their popularity), they do not necessarily take into account, or reflect on, the needs and personal characteristics of each specific case. It is also remarkable that around $20 \%$ of staff members considered that, when a PLWD shows apathy, the common response is to do nothing and ignore the situation, and another $20 \%$ said that they did not know how apathy is commonly managed in their institution, numbers that are consistent with a view of apathy as a minor problem, since PLWD with apathy do not usually interfere with the everyday functioning of long-term care institutions, even if staff pay them little or no attention. ${ }^{17}$

Strategies that seem to be more complex and tailored (those based on person-centered care) are also used, but they were perceived as common practice by less than half of the participants. The conclusion we can draw is that the approach to the management of apathy in PLWD in many cases is far from ideal, and that there is room for improvement. When it is managed without taking into account the personal and environmental circumstances surrounding the situation, some success in 'activating' the PLWD may be achieved, but there are several implicit risks. The first is the risk of applying flawed (or at least non-optimal) strategies, forgetting important personal and environmental factors involved in the situation. The second is the risk of providing dehumanizing and disempowering care in which the PLWD's perspective is ignored. Unfortunately, quick and simple strategies, sometimes based on practices that have proved effective in previous situations or for other persons, may be an all too easy resort for professionals, particularly in cases of heavy workloads and understaffing. ${ }^{48}$

These results lead to the third main finding of our study regarding the gap between common and best practices. This gap was particularly large in two categories: no intervention, which was the least frequently mentioned as best practice, and person-centered strategies, which were the most frequently mentioned as best practice. These differences suggest that staff (or at least some of them) are aware that not intervening would not be an option in the ideal care of apathy in PLWD, and a more tailored and complex approach to managing the situation, taking into account relational and biographical aspects, would be desirable, but that for some reason, they cannot implement in practice what they think would be right. Consequently, there is potential for improvement if barriers to these good intentions can be identified and minimized. Although our study does not provide any evidence concerning this issue, poor working conditions in a stressful context, as mentioned above, may be behind this gap, and further research is needed to ascertain if this factor (or other ones) accounts for the lack of implementation of the best possible practice according to staff.

Finally, our results revealed differences between assistant carers and technical staff. In terms of common practices, technical staff mentioned not intervening as the usual way to treat apathy in PLWD more frequently than care assistants. In contrast, care assistants, who are at the front line of providing care, mentioned behavior-focused strategies as the most frequent way to deal with apathy, and that they tend to share the situation with someone else more frequently. Regarding best practices, they seemed far less aware than the technical staff of person-centered care as the ideal way to deal with apathy. These assistant carers' preference for simple and direct interventions could reflect their lower level of training, but also their previous experiences with situations of this kind or the urgency with which they have to make decisions on an everyday basis. In this context, sharing the situation with someone could also be a solution, as well as an indicator of a lack of resources or lack of autonomy. This profile of assistant carers' preferences is particularly relevant if we take into account that, as the main front-line care providers, their decisions and actions currently define the way care is provided to PLWD living in institutions. While technical staff in particular recognized personcentered care as the best way (although not the only one, since most of them also mention behavior-focused strategies) to approach apathy in PLWD, this kind of strategy struggles to prevail as the standard to deal with apathy, particularly among those in charge of frontline care, that is, the care assistants.

This study does have some limitations that need to be taken into account when interpreting the results. Firstly, this was an exploratory and single-country study in which only a few purposively selected long-term care facilities participated. So, the results are not necessarily generalizable to other facilities and geographical contexts and need to be confirmed by further research. The design of a study including a larger and more diverse sample of facilities and professionals quantitatively evaluating the range of strategies that appeared in our findings could be a fruitful avenue to determine in more detail how apathy is approached in PLWD living in institutions, and which factors predict preferences for certain strategies. Secondly, the use of vignettes as a response-gathering technique, although a useful way to approach exploratory studies like this ${ }^{49}$, also has its own limitations. For instance, vignettes lead participants to consider a very generic situation, without the nuances and complexities present in their real daily experiences, and thus changing the description of the vignette (e.g. adding details such as the degree of cognitive impairment or the gender of the PLWD) could impact on the participants' responses. Future studies collecting and analyzing real situations experienced by staff would reinforce the validity of the reactions and strategies proposed by the participants. Finally, the study did not include measures of staff's perceptions of the success of their interventions. A study of these perceptions might have helped to explain why certain interventions (e.g., behavior-focused interventions) are so prevalent as common and best practices.

\section{Conclusion}

To sum up, our study contributes to the literature by identifying common and best practices that staff mention for managing apathy, one of the more common and overlooked problems present in PLWD living in long-term care institutions. It highlights that there is still plenty of room for improvement, particularly among frontline care providers, for the development and implementation of person-centered strategies when dealing with apathy, a situation in which resorting to behavior-focused strategies, or simply do nothing, could be very tempting.

\section{Relevance to clinical practice}

The results have some practical implications. Firstly, to avoid the variety in responses to a similar situation, or acting without taking into account factors that may influence the presence of apathy in a specific person, it would be important to design guidelines to approach apathy in PLWD living in long-term institutions. Guidelines, 
as well as helping to harmonize how staff approach these situations, could also promote a tailored, person-centered approach and should be made available particularly for care assistants. This leads to a second practical implication, which has to do with the relevance of training for managing apathy according to person-centered care principles. Although it is already well-known that training is key to proper care for PLWD living in institutional settings ${ }^{50}$, our results suggest that staff development initiatives should take into account work position as a relevant variable, since their experience, knowledge and function in the organization is different. For instance, in the case of assistant carers, training could take into account their experience and common practices in dealing with apathy; then, grounded on this experience, it could aim to develop the skills and self-reliance required to reflect on such practices, find ways to improve them, and manage complex situations such as the one posed in this study. Finally, it would be important to identify why person-centered care strategies, even when recognized (particularly by technical staff) as the best way to manage apathy in PLWD, are not more widely applied in common practice. Identifying these barriers would be the first step to designing ways to overcome them.

\section{Declaration of Competing Interest}

The authors declare no conflict of interest.

\section{Appendix. Interview guide (only responses to question 5 are analyzed in this article)}

1. Based on your experience, what are the capacities and skills that a person with dementia loses in the early stages of the illness?

2. Based on your experience, what are the capacities and skills that a person with dementia keeps until the final stages of the illness?

3. Imagine that you have a new workmate, without any experience in caring people living with dementia. What key pieces of advice would you give to help him/her to offer the best quality care?

4. In your opinion, what is the mistake most frequently by professionals when caring for a person living with dementia?

Now we will describe two situations involving a person with dementia living in a nursing home:

5. A person with dementia living in this nursing home spends all day sitting alone, without talking to anyone, and refuses to participate in any activity proposed by the staff.

- Have you experienced an event like this in your time in this nursing home?

- If so, what do your workmates in this nursing home commonly do in this situation?

- What should be done in such a situation?

6. A person with dementia living in this nursing home refuses to eat, and resists any attempt to help made by your workmates, even yelling and hitting

- Have you experienced an event like this in your time in this nursing home?

- If so, what do your workmates in this nursing home commonly do in this situation?

- What should be done in such a situation?

\section{References}

1. Siafarikas N, Selbaek G, Fladby T, Šaltytė Benth J, Auning E, Aarsland D. Frequency and subgroups of neuropsychiatric symptoms in mild cognitive impairment and different stages of dementia in Alzheimer's disease. Int Psychogeriatr. 2018;30 (1):103-113. https://doi.org/10.1017/S1041610217001879.

2. Majic T, Pluta JP, Mell T, Aichberger MC, Treusch Y, Gutzmann H, Heinz A, Rapp MA The pharmacotherapy of neuropsychiatric symptoms of dementia: a cross-sectional study in 18 homes for the elderly in Berlin. Dtsch Arztebl Int. 2010;107 (18):320-327. https://doi.org/10.3238/arztebl.2010.0320.

3. Onyike CU, Sheppard JM, Tschanz JT, Norton MC, Green RC, Steinberg M, WelshBohmer KA, Breitner JC, Lyketsos CG. Epidemiology of apathy in older adults: the Cache County Study. Am J Geriatr Psychiatry. 2007;15(5):365-375. https://doi.org/ 10.1097/01.JGP.0000235689.42910.0d.

4. Starkstein S, Hayhow B. Apathy in Dementia: Time to StandUp. Am J Geriatr Psychiatry. 2019;27(4):406-407. https://doi.org/10.1016/j.jagp.2018.12.035.

5. Robert P, Onyike CU, Leentjens AF, Dujardin K, Aalten P, Starkstein S, Verhey FR, Yessavage J, Clement JP, Drapier D, Bayle F, Benoit M, Boyer P, Lorca PM, Thibaut F, Gauthier S, Grossberg G, Vellas B, Byrne J. Proposed diagnostic criteria for apathy in Alzheimer's disease and other neuropsychiatric disorders. Eur Psychiatry. 2009;24(2):98-104. https://doi.org/10.1016/j.eurpsy.2008.09.001.

6. Starkstein SE, Leentjens AF. The nosological position of apathy in clinical practice. $J$ Neurol Neurosurg Psychiatry. 2008;79(10):1088-1092. https://doi.org/10.1136/ jnnp.2007.136895.

7. Lanctôt KL, Agüera-Ortiz L, Brodaty H, Francis PT, Geda YE, Ismail Z, Marshall GA, Mortby ME, Onyike CU, Padala PR, Politis AM, Rosenberg PB, Siegel E, Sultzer DL, Abraham EH. Apathy associated with neurocognitive disorders: recent progress and future directions. Alzheimers Dement. 2017;13(1):84-100. https://doi.org/ 10.1016/j.jalz.2016.05.008.

8. Mohammad D, Ellis C, Rau A, Rosenberg PB, Mintzer J, Ruthirakuhan M, Herrmann N, Lanctôt KL. Psychometric properties of apathy scales in Dementia: a systematic review. J Alzheimers Dis. 2018;66(3):1065-1082. https://doi.org/10.3233/JAD-180485.

9. Vilalta-Franch J, Calvó-Perxas L, Garre-Olmo J, Turró-Garriga O, López-Pousa S. Apathy syndrome in Alzheimer's disease epidemiology: prevalence, incidence, persistence, and risk and mortality factors. J Alzheimers Dis. 2013;33(2):535-543. https://doi.org/10.3233/JAD-2012-120913.

10. Goris ED, Ansel KN, Schutte DL. Quantitative systematic review of the effects of non-pharmacological interventions on reducing apathy in persons with dementia. J Adv Nurs. 2016;72(11):2612-2628. https://doi.org/10.1111/jan.13026.

11. Kolanowski A, Boltz M, Galik E, Gitlin LN, Kales HC, Resnick B, Van Haitsma KS, Knehans A, Sutterlin JE, Sefcik JS, Liu W, Petrovsky DV, Massimo L, Gilmore-Bykovskyi A, MacAndrew M, Brewster G, Nalls V, Jao YL, Duffort N, Scerpella D. Determinants of behavioral and psychological symptoms of dementia: a scoping review of the evidence. Nurs Outlook. 2017;65(5):515-529. https://doi.org/10.1016/j.outlook.2017.06.006.

12. Dauphinot V, Delphin-Combe F, Mouchoux C, Dorey A, Bathsavanis A, Makaroff Z, Rouch I, Krolak-Salmon P. Risk factors of caregiver burden among patients with Alzheimer's disease or related disorders: a cross-sectional study. J Alzheimers Dis. 2015;44(3):907-916. https://doi.org/10.3233/JAD-142337.

13. Feast A, Moniz-Cook E, Stoner C, Charlesworth G, Orrell M. A systematic review of the relationship between behavioral and psychological symptoms (BPSD) and caregiver well-being. Int Psychogeriatr. 2016;28(11):1761-1774. https://doi.org/ 10.1017/S1041610216000922.

14. Massimo L, Kales HC, Kolanowski A. State of the science: apathy as a model for investigating behavioral and psychological symptoms in dementia. J Am Ger Soc. 2018;66(suppl 1):S4-S12. https://doi.org/10.1111/jgs.15343.

15. Brodaty H, Burns K. Nonpharmacological management of apathy in dementia: a systematic review. Am J Geriatr Psychiatry. 2012;20(7):549-564. https://doi.org/ 10.1097/JGP.0b013e31822be242.

16. van Reekum R, Stuss DT, Ostrander L. Apathy: Why Care? Focus (Am Psychiatr Publ). 2016;14(4):523-532. https://doi.org/10.1176/appi.neuropsych.17.1.7.

17. van der Linde RM, Matthews FE, Dening T, Brayne C. Patterns and persistence of behavioural and psychological symptoms in those with cognitive impairment: the importance of apathy. Int J Geriatr Psychiatry. 2017;32(3):306-315. https://doi.org/ 10.1002 /gps.4464.

18. Starkstein SE, Jorge R, Mizrahi R, Robinson RG. The construct of minor and major depression in Alzheimer's disease. Am J Psychiatry. 2005;162(11):2086-2093. https://doi.org/10.1176/appi.ajp.162.11.2086.

19. Holmes C, Knights A, Dean C, Hodkinson S, Hopkins V. Keep music live: music and the alleviation of apathy in dementia subjects. Int Psychogeriatr. 2006;18(4):623630. https://doi.org/10.1017/S1041610206003887.

20. Raglio A, Bellelli G, Traficante D, Gianotti M, Ubezio MC, Villani D, Trabucchi M. Efficacy of music therapy in the treatment of behavioral and psychiatric symptoms of dementia. Alzheimer Dis Assoc Disord. 2008;22(2):158-162. https://doi.org/ 10.1097/WAD.0b013e3181630b6f.

21. Vink AC, Birks JS, Bruinsma MS, Scholten RJ. Music therapy for people with dementia. Cochrane Database Syst Rev. 2004(3) CD003477. https://doi.org/10.1002/ 14651858.CD003477.pub2.

22. Tang Q, Zhou Y, Yang S, Thomas WKS, Smith GD, Yang Z, Yuan L, Chung JW. Effect of music intervention on apathy in nursing home residents with dementia. Geriatr Nurs. 2018;39(4):471-476. https://doi.org/10.1016/j.gerinurse.2018.02.003.

23. Lane-Brown AT, Tate RL. Apathy after acquired brain impairment: a systematic review of non-pharmacological interventions. Neuropsychol Rehabil. 2009;19 (4):481-516. https://doi.org/10.1080/09602010902949207.

24. Chancellor B, Duncan A, Chatterjee A. Art therapy for Alzheimer's disease and other dementias. J Alzheimers Dis. 2014;39(1):1-11. 
25. Deshmukh SR, Holmes J, Cardno A. Art therapy for people with dementia. Cochrane Database Syst Rev. 2018;9:(9) CD011073. https://doi.org/10.1002/14651858. CD011073.pub2.

26. Motomura N, Yagi T, Ohyama $\mathrm{H}$. Animal assisted therapy for people with dementia. Psychogeriatr. 2004;4(2):40-42. https://doi.org/10.1111/j.1479-8301.2004.00062.x.

27. Rabins PV, Blacker D, Rovner BW, Rummans T, Schneider LS, Tariot PN, Blass DM, Steering Committee on Practice GuidelinesMcIntyre JS, Charles SC, Anzia DJ, Cook IA, Finnerty MT, Johnson BR, Nininger JE, Schneidman B, Summergrad P, Woods SM, Berger J, Cross CD, Brandt HA, Margolis PM, Shemo JP, Blinder BJ, Duncan DL, Barnovitz MA, Carino AJ, Freyberg ZZ, Gray SH, Tonnu T, Kunkle R, Albert AB, Craig T], Regier DA, Fochtmann LJ. American Psychiatric Association practice guideline for the treatment of patients with Alzheimer's disease and other dementias. second edition. Am J Psychiatry. 2007;164(12 Suppl):5-56.

28. Niu YX, Tan JP, Guan JQ, Zhang ZQ, Wang LN. Cognitive stimulation therapy in the treatment of neuropsychiatric symptoms in Alzheimer's disease: a randomized controlled trial. Clin Rehabil. 2010;24(12):1102-1111. https://doi.org/10.1177/ 0269215510376004.

29. Baker R, Bell S, Baker E, Gibson S, Holloway J, Pearce R, Dowling Z, Thomas P, Assey $\mathrm{J}$, Wareing LA. A randomized controlled trial of the effects of multi-sensory stimulation (MSS) for people with dementia. Br J Clin Psychol. 2001;40(1):81-96. https:/| doi.org/10.1348/014466501163508.

30. van Weert JC, van Dulmen AM, Spreeuwenberg PM, Ribbe MW, Bensing JM. Behavioral and mood effects of snoezelen integrated into 24-hour dementia care. J Am Geriatr Soc. 2005;53(1):24-33. https://doi.org/10.1111/j.1532-5415.2005.53006.x.

31. Kolanowski A, Litaker M, Buettner L, Moeller J, Costa Jr. PT. A randomized clinical trial of theory-based activities for the behavioral symptoms of dementia in nursing home residents. J Am Geriatr Soc. 2011;59(6):1032-1041. https://doi.org/10.1111/ j.1532-5415.2011.03449.x.

32. Lam LC, Lui VW, Luk DN, Chau R, So C, Poon V, Tam P, Ching R, Lo H, Chiu J, Fung A, Ko FS. Effectiveness of an individualized functional training program on affective disturbances and functional skills in mild and moderate dementia-a randomized control trial. Int J Geriatr Psychiatry. 2010;25(2):133-141. https://doi.org/10.1002/gps.2309.

33. Raber C, Teitelman J, Watts J, Kielhofner G. A phenomenological study of volition in everyday occupations of older people with dementia. Br J Occup Ther. 2010;73 (11):498-506

34. Hobson P. Enabling people with dementia: Understanding and implementing personcentred care. 3rd ed. Springer; 2019.

35. Fleming R, Goodenough B, Low LF, Chenoweth L, Brodaty H. The relationship between the quality of the built environment and the quality of life of people with dementia in residential care. Dementia (London). 2016;15(4):663-680. https://doi. org/10.1177/1471301214532460.

36. Tappen RM, Williams CL. Therapeutic conversation to improve mood in nursing home residents with Alzheimer's disease. Res Gerontol Nurs. 2009;2(4):267-275. https://doi.org/10.3928/19404921-20090428-02.

37. Tadaka E, Kanagawa K. Effects of reminiscence group in elderly people with Alzheimer disease and vascular dementia in a community setting. Geriatr Gerontol Int. 2007;7(2). https://doi.org/10.1111/j.1447-0594.2007.00381.x.167-3.
38. Hsieh CJ, Chang C, Su SF, Hsiao YL, Shih YW, Han WH, Lin CC. Reminiscence group therapy on depression and apathy in nursing home residents with mild-to-moderate dementia. J Exp Clin Med. 2010;2(2). https://doi.org/10.1016/S1878-3317(10) 60012-5. 72-8.

39. American Geriatrics. Society. American Association for Geriatric. Psychiatry. Consensus statement on improving the quality of mental health care in U.S. nursing homes: management of depression and behavioral symptoms associated with dementia. J Am Geriatr Soc. 2003;51(9):1287-1298. https://doi.org/10.1046/ j.1532-5415.2003.51415.x.

40. Bennett MK, Ward EC, Scarinci NA. Exploratory investigation of communication management in residential-aged care: a comparison of staff knowledge, documentation and observed resident-staff communication. Int J Lang Commun Disord. 2016;51(3):296-309. https://doi.org/10.1111/1460-6984.12207.

41. Villar F, Celdrán M, Serrat R, Fabà J, Martínez T. Staff responses to residents exposing their genitals in public in long-term care settings: The gap between common and perceived best practices. J Clin Nurs. 2019;28(19-20):3575-3581. https://doi. org/10.1111/jocn.14952.

42. Leone E, Deudon A, Bauchet M, Laye M, Bordone N, Lee JH, Piano J, Friedman L, David R, Delva F, Brocker P, Yesavage J, Robert PH. Management of apathy in nursing homes using a teaching program for care staff: the STIM-EHPAD study. Int J Geriatr Psychiatry. 2013;28(4):383-392. https://doi.org/10.1002/gps.3836.

43. Coogle CL, Parham IA, Rachel CA. Job satisfaction and career commitment among Alzheimer's care providers: addressing turnover and improving staff empowerment. Am J Alzheimers Dis Other Demen. 2011;26(7):521-527. https://doi.org/ 10.1177/1533317507303439.

44. Villar F, Celdrán M, Serrat R, Fabà J, Genover M. Martínez MT Sexual situations in Spanish long-term care facilities: Which ones cause the most discomfort to staff? Sex Res Social Policy. 2019;16:446-454. https://doi.org/10.1007/s13178-018-0346-9.

45. Vaismoradi M, Turunen $\mathrm{H}$, Bondas T. Content analysis and thematic analysis: implications for conducting a qualitative descriptive study. Nurs Health Sci. 2013;15 (3):398-405. https://doi.org/10.1111/nhs.12048.

46. Aalten P, de Vugt ME, Lousberg R, Korten E, Jaspers N, Senden B, Jolles J, Verhey FR. Behavioral problems in dementia: a factor analysis of the neuropsychiatric inventory. Dement Geriatr Cogn Disord. 2003;15(2):99-105. https://doi.org/10.1159/ 000067972.

47. Wood S, Cummings JL, Hsu MA, Barclay T, Wheatley MV, Yarema KT, Schnelle JF. The use of the neuropsychiatric inventory in nursing home residents. characterization and measurement. Am J Geriatr Psychiatry. 2000;8(1):75-83. https://doi.org/ 10.1097/00019442-200002000-00010.

48. Zhang Y, Punnett L, Mawn B, Gore R. Working conditions and mental health of nursing staff in nursing homes. Issues Ment Health Nurs. 2016;37(7):485-492. https://doi.org/10.3109/01612840.2016.1162884. Jul.

49. Braun V, Clarke V. Successful qualitative research: a practical guide for beginners. Sage. 2013.

50. Shinan-Altman S, Werner P, Cohen M. Social workers' and nurses' illness representations about Alzheimer disease: an exploratory study. Alzheimer Dis Assoc Disord. 2014;28(1):73-78. https://doi.org/10.1097/WAD.0000000000000001. 